\title{
Enabling Greater Private Sector Participation in Health Research in the Philippines
}

\author{
Melanio U. Mauricio III, Maria Angeli C. Magdaraog, Kristine Mae P. Magtubo and Lester Sam A. Geroy \\ Alliance for Improving Health Outcomes
}

\begin{abstract}
Objective. This study reviewed the current health research and development environment in the Philippines with respect to the engagement between the public and private sectors. The overall objective was to identify the role of the private sector in health research and identify barriers and opportunities for successful public-private health research partnerships.

Methods. Key informant interviews were conducted using a semi-structured interview tool. Secondary data such as annual reports and project funding documents from the Philippine Council for Health Research and Development were also analyzed.

Results. The roles of the private sector when engaging with the public sector for research and development were identified as generators, funders, and adopters of research. Information gathered showed that there were several institutional and practice barriers to the successful collaboration of the public and private sectors, however there were also lessons learned from the successes of cases such as the Axis-Knee System, Sambong, and Lagundi technologies.

Conclusion. The collaboration and partnership of the public and private sectors can be mutually beneficial. Government initiative to increase the ease of collaboration with the private sector in health research was found to be a necessary step to stimulate a productive health research environment.
\end{abstract}

Key Words: private sector, public-private partnership, health research

\section{INTRODUCTION}

Private sector participation in health care is a widely discussed subject that has been studied extensively. ${ }^{1,2}$ Studies place considerable value into a multisectoral approach in order to maximize health gains. In resource-limited areas, particularly low- and middle-income countries, the participation of the private sector in the health system proves valuable. Evidence suggests that greater private sector participation in health care improves at least the intermediate health outcomes, even in developing countries like the Philippines. ${ }^{3,4}$ The case for private sector participation in research is likewise well-studied, with evidence suggesting that collaborative research with the private sector advances scientific knowledge, improves research impact, boosts productivity, and drives economic growth. ${ }^{5}$

Currently, very little to no research has been done to evaluate the impact of the private sector in health research for developing countries such as the Philippines. The private

Corresponding author: Lester Sam A. Geroy, MD, MPH, MSc Alliance for Improving Health Outcomes

62 West Avenue, Quezon City 1104, Philippines

Telephone: +6392 66243952

Email: lelim22@yahoo.com sector has a larger market share in the Philippines, although robust indices are lacking. For instance, in 2017, PhilHealth benefit claims to the private sector formal economy amounted to P18.1 billion (from P17.4 billion in 2016), almost triple to 
that of government which was only P6.9 billion (from P7.4 billion in 2016). ${ }^{6}$ This did not include user fees, co-payments, and other health expenditures from out-of-pocket. However, certain studies from high-income countries revealed that public investments in private health research and development were returned as GDP gains. ${ }^{7}$ Although some studies were conducted to assess public-private partnerships, focus had mostly been given to health care and service delivery.

In the field of health research and development, the term "private sector" encompasses a multitude of players and actors, which may include privately-owned higher education institutes (HEIs), private non-profit organizations, and private enterprises. ${ }^{8}$ This study limited the term "private sector" to private businesses in order to differentiate the participation of private businesses from other private sector actors such as HEIs and NGOs. This study looked at the role of the private sector in the Philippines' health research landscape by examining activities funded, supported, or monitored by the Department of Science and Technology and other partnerships between the public and private sectors. Through a review of the current health research environment and a discussion of cases of private sector engagement, this paper aimed to identify the role of the private sector in health research and identify barriers and opportunities for successful public-private health research partnerships.

\section{METHODS}

Nine key informant interviews with players from the public and private sectors were conducted to gain insight on the interactions of the two sectors in the field of health research and development. Interviews were conducted with representatives from the Department of Health (DOH), the Department of Science and Technology (DOST), USAID Stride, University of the Philippines-Manila Technology Transfer and Business Development Office, the Food and Drug Administration (FDA), Orthopaedic International Inc. (OII), and pharmaceutical companies and associations such as the Pharmaceutical and Healthcare Association of the Philippines (PHAP) and Pascual Laboratories, Inc. Four of these represented the private sector (USAID Stride, OII, PHAP, and Pascual Laboratories), while the rest represented public stakeholders. Interviewees were nominated based on a snowball sampling method. The interviewees were selected based on their known involvement in health research and development. Out of the nine interviews, seven were conducted face-to-face and two were conducted online through e-mail. A semi-structured interview method with open-ended questions was used with tools that were adapted to fit the roles of the interviewees. Interviewees were requested to sign the consent forms prior to interviews. Interviews were recorded and transcribed. The data collected underwent thematic analysis by hand coding information into categories to help identify roles of the private sector in health research and the prevailing gaps needed to be addressed.
To supplement data collected from key informant interviews, secondary data analysis was also conducted. Documents reviewed were the annual reports of the Philippine Health Research Registry (PHRR) and the Philippine Council for Health Research and Development (PCHRD) project funding documents. Data collected from these documents included the number of researches registered per year from 2012 to 2017, the number of researches funded by the private sector from 2012 to 2017, and the research and development (R\&D) projects supported by PCHRD.

\section{RESULTS AND DISCUSSION}

\section{Private sector engagement in health research in the Philippines}

Interviews revealed that the private sector had three main roles in health research: generator, funder, or adopter (Figure 1). These private-public partnerships and interactions were broadly summarized and mapped out based on findings from key informant interviews. The private sector may act as generators of research and, as such, become the main proponents of their own studies. While some private sector entities may independently fund their own research, they may interact with public and private funding agencies for research grants or with other government agencies for services such as testing or certification.

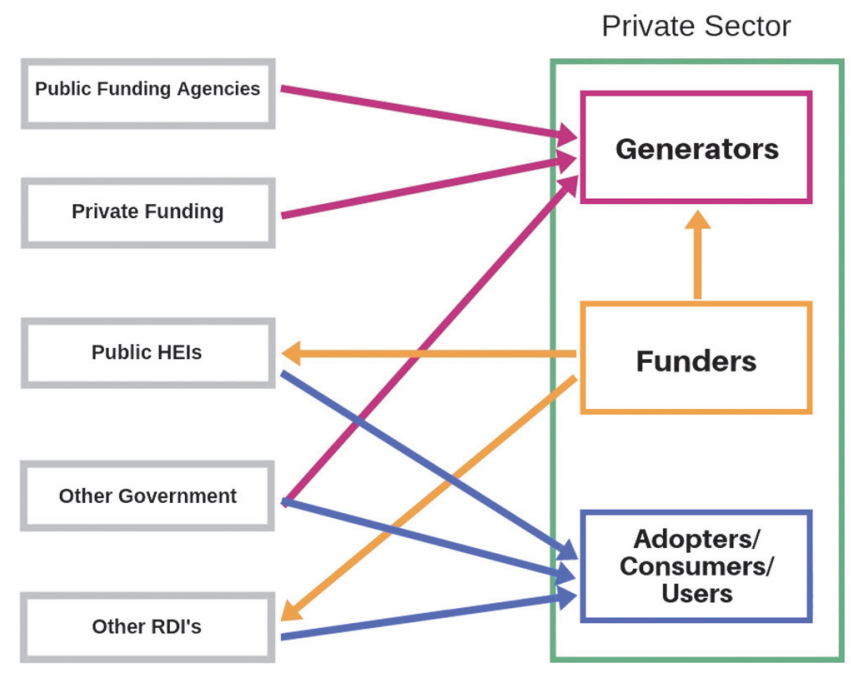

Figure 1. Interactions of the Private Sector with Other Actors.

PCHRD monitors private sector engagement through monitoring of the sources and recipients of research funding. Figure 2 shows the amount of support in the form of grants given by the PCHRD by sector of performance from 20102013, and then for 2015. Half (51.88\%) of these grants went to public HEIs while about a third (30.29\%) was shared by the "private sector", of which private businesses had the least share (4.70\%). ${ }^{9}$ Less than a third $(26.92 \%)$ was received by other government agencies conducting research activities. 


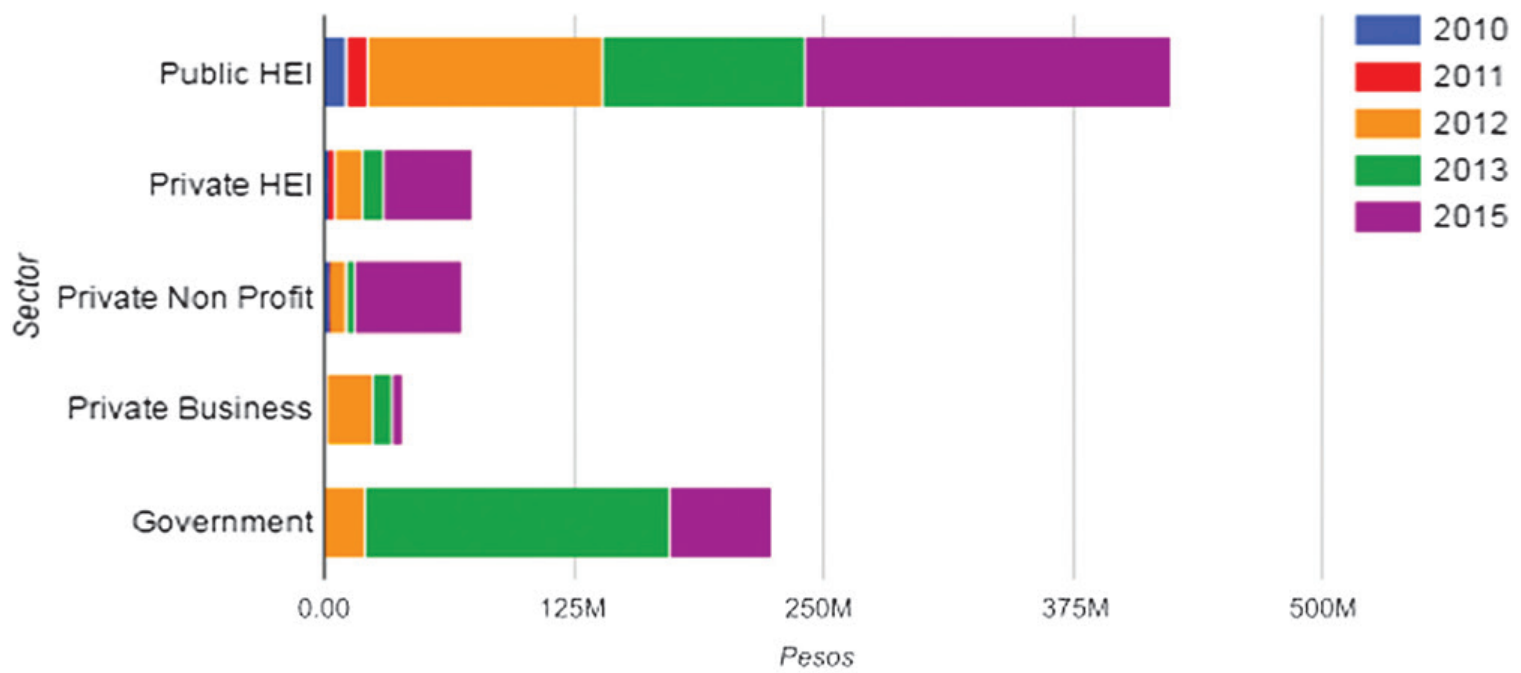

Figure 2. Amount of Funding for R\&D projects supported by PCHRD 2010 to 2013, 2015. ${ }^{8}$

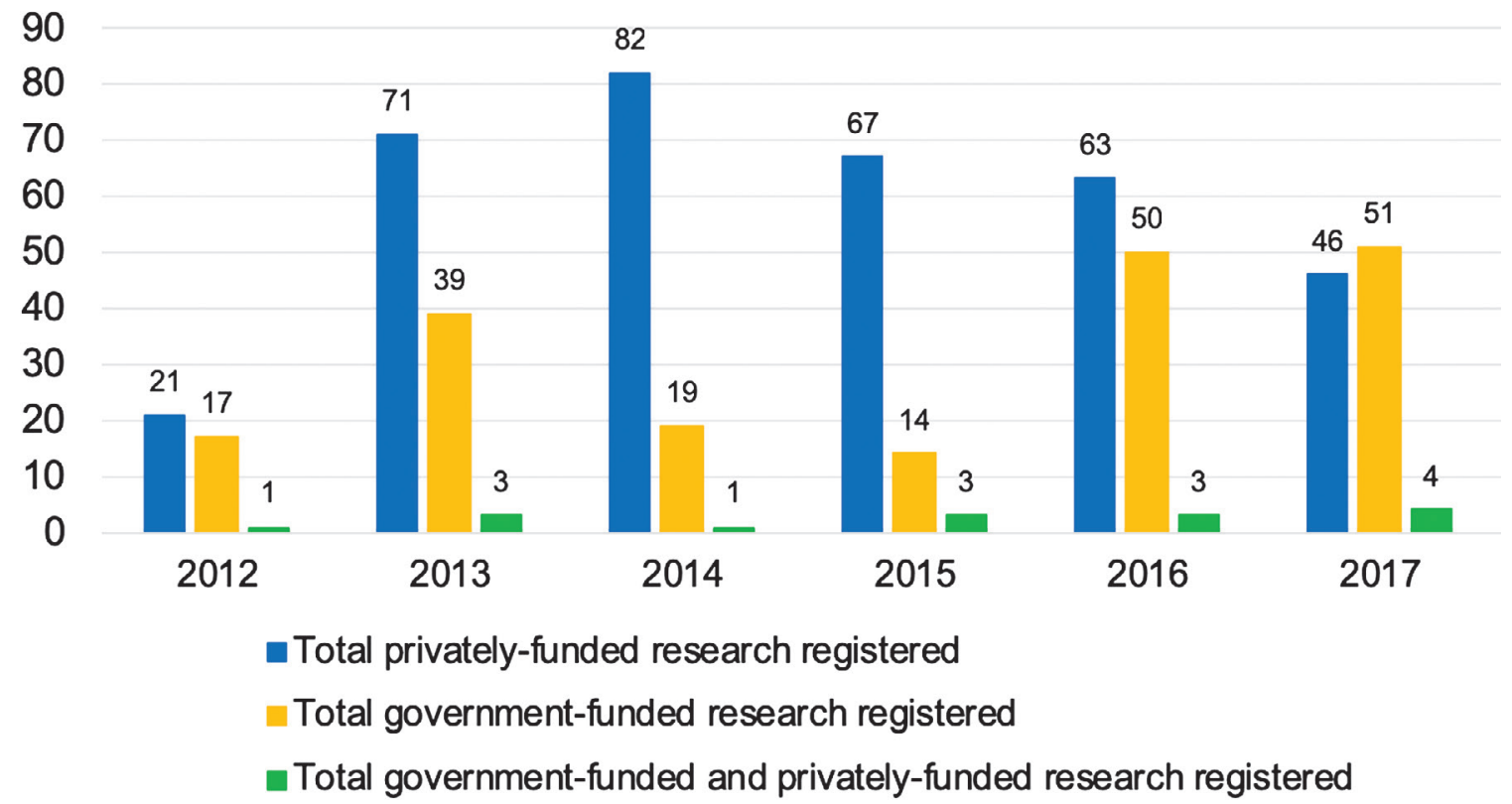

Figure 3. Sources of funding of registered health research from 2012 to $2017 .{ }^{11}$

As funders, the private sector may commission public or private HEIs and research development institutes (RDIs) to conduct research and development studies. Figure 3 illustrates the sources of funding for health research, as stated in the PHRR annual report from 2012 to 2017. Over the six-year period, the first five years were primarily driven by the private sector funding. An average of $63 \%$ percent of registered health research was funded by the private sector, which primarily comprised of private businesses. Conversely, $35 \%$ of the funding was sourced from the government. ${ }^{9}$ The data were based on registered research. It is unclear what caused the increased private in 2013 and 2014, and what explains the decline of private funding relative to public funding. No analysis is currently being done to investigate this.
While efforts by agencies like the Intellectual Property Office-Philippines (IPOPHL) has sparked a whirlwind of intellectual property protection activities in HEIs and RDIs, capacity-building activities and institutional arrangements have not been made to ensure that these organizations are able to market their portfolio effectively. ${ }^{10}$ Their evaluation further confirms the interviews conducted by stating that most businesses would invest in ready-to-market technology. The health sector (or health research sector) has the potential to produce such products, e.g. biomedical devices, traditional medicines, and health information technology applications, among others. There is currently no incentive for the private sector to be involved in earlystage research. 


\section{Public-Private Sector Health Research Engagements}

While there are limited existing public-private collaboration for health research and development in the Philippines, three cases stood out as notable achievements based from interviews and gathered secondary information- the Axis Knee System collaboration between DOST and OII, and the development of Sambong and Lagundi products by PCHRD, NIRPROMP, and Pascual Laboratories, Inc.

\section{The Axis Knee System}

After conceptualization of the Axis Knee System, Dr. Ramon Gustilo contacted DOST to collaborate with the government on further R\&D activities. It was his firm belief that the government should be the key player in $R \& D$ activities in the country. This led to the inking of a research grant awarded to his company, Orthopaedic International, Inc. (OII) and the birth of the Axis Knee System, the country's first private-public partnership in biomedical device development. OII is currently manufacturing and selling the Axis Knee System so that Filipinos can avail of a cheaper and reliable knee implant.

Trust between DOST and OII in delivering the product was important in inspiring a relationship based on openness between OII and DOST, who have continued to be partners in commercializing the Axis Knee System. Beyond funding support, DOST aided in the market entry of the product through promotional activities in DOST events. Another good practice in the collaboration was the assignment of a focal person from PCHRD to facilitate all communications between OII and PCHRD.

While the collaboration was mostly successful, there were some points for improvement identified by the key informant. One of the most important points was regarding the funding cycle for projects supported by government funds. Aside from delays in the release of funds, the funding support from PCHRD had to be reevaluated yearly, which meant projects could be discontinued if there was no proof of significant progress. In the case of the Axis Knee System development, the research and development activities continued despite the delay or temporary halting in funding because of OII's resources as a private corporation. However, this funding cycle is one of the reasons why small enterprises or individual researchers are often afraid to depend on government support for their R\&D activities.

\section{Blumea balsamifera (Sambong) and Vitex negundo (Lagundi)}

Dr. Nelia Maramba, a professor of pharmacology, at the University of the Philippines Manila was the designated principal investigator for a project funded by DOST-PCHRD in collaboration with the National Integrated Research Program on Medicinal Plants (NIRPROMP) to study ten medicinal plants which included Blumea balsamifera (Sambong) and Vitex negundo
(Lagundi), flowering plants that are both abundant in the Philippines. ${ }^{12}$

The two plants were among the first medicinal plants patented in the Philippines. Sambong was applied for a patent as a diuretic and for kidney stone dissolution, while Lagundi was patented as a cough medicine formula. ${ }^{13}$ As the funding agency, DOST PCHRD owned the patent and utility model for Sambong and Lagundi. They licensed the two herbal medicines to Pascual Laboratories, Inc. in order to promote commercialization of the products. From this licensing deal, Pascual Laboratories remitted an initial remittance of $\mathrm{P} 164,018.85 .{ }^{12}$ In 2006, the patent for Sambong was finally approved and became available for distribution to the market.

In 2009, RA 10055 or the Technology Transfer Law was signed. Under this law, funding agencies must assign the IP in their portfolio to the RDIs. PCHRD assigned the patent for Lagundi and Sambong to UP Manila. In 2010, UP reported an income of P13,856,915.13 from Sambong and Lagundi from Pascual Laboratories, which represented an 84-fold increase in their revenue in only 13 years. ${ }^{12}$

According to the key informant, they were successful in patenting Sambong because of the rigorous studies that Dr. Maramba's team conducted. Prior to the patenting of Sambong, they were already licensing some of the products to makers of galenicals. To this day, licensees rely on the rigor of Dr. Maramba's studies to get them through the registration process of the Food and Drug Administration (FDA). If the licensees had to do this themselves, it would be time and resource-consuming.

Another critical factor in the success of these herbal medicines is the openness for collaboration of the research team and the private sector. Even before the patent was awarded, many pharmaceutical companies showed interest in the herbal medicines. Companies were willing to bet early on the successes of herbal medicines. PCHRD saw this as a prompt to release a non-exclusive licensing agreement system. It was crucial that R\&D clinical tests conducted by NIRPROMP affirmed the safety and efficacy of the medicines for the licensees to commercialize the products.

\section{Challenges and success factors for private sector engagement}

After exploring the roles and dynamics of the private sector in health research, several salient points have come to view. The interviews and studies have revealed certain challenges for the private sector to act as a generator, funder, or adopter of research. These challenges include various institutional barriers and the perception of private sector involvement in health research.

Despite these challenges, the aforementioned cases of public-private health research partnerships have highlighted key factors to fruitful and profitable health innovations. These factors are important considerations that could equip and enable further collaborations for health research. 


\section{Institutional barriers hinder private sector engagement in health research}

As a funder of public HEI research, one of the barriers which hinders private sector participation is the lack of support, incentives, and rewards for a public-private collaboration. Associating with industry or business is not often encouraged because of the possibility of conflict of interest.

Informants cited the complexity of dealing with HEIs as one of the reasons for not acquiring HEI-developed research products. One informant also mentioned university revenue expectations as a deterrent to true collaborations. There is also a widely-held notion that businesses would like full control of intellectual property, which often results in hesitation of the researchers themselves to commercialize their research. Experts in intellectual property and health research will be very helpful in this aspect.

Based on key informant interviews, private sector access to government funds for research is often limited due to several factors. The extensive bureaucratic process of government application, clearance, and monitoring can be burdensome and slows the progress for private sector researchers. Additionally, the fund release scheme is a point of uncertainty in the continuity of the research activity.

From the private sector perspective, informants cited the complexity in providing funds for research to HEIs and RDIs, especially those that are government-affiliated or publicly-owned. They reported difficulty in identifying a point person, slow government procurement process, and the complex process of decision-making as hindrances to sourcing expertise from HEIs and RDIs for their R\&D needs.

Key informants emphasized institutional processes, e.g. access to funds and procurement mechanisms as the main obstacle to public-private collaboration in research. Strengthening should focus on policy development and capacity building to enhance collaboration and procurement, and not capacity building to implement research. Government officials and staff must have the capacity to maximize existing procurement mechanisms that would favor research.

\section{Need to change knowledge and attitudes on private sector engagement in health research}

There are also barriers to private sector engagement in health research. There is an impression that these funds are only for public HEIs and there is no awareness of the availability of these funds. Hence, it is more common that private businesses fund their own R\&D activities.

It can also be perceived as unglamorous for HEIs to engage the private sector as it seldom results in prize-winning discoveries, publishable studies, or patentable intellectual property, which are often the basis for promotion within the academe. Most projects never transition into long-term partnerships. ${ }^{5,14}$ This is quite important in establishing trust-based relationships with the private sector, which is often the entry point for exchange of the knowledge and skills in health research.

\section{Good lessons from existing private sector participation in health research}

From the cases mentioned earlier, clear benefits from the active participation of the private sector in health research were established. In both cases, research activities resulted in products which created economic activity. The private sector invested in activities that created more research, whether in the form of royalties paid to the RDI or by direct spending. The case studies also illustrated how collaboration created a win-win situation for health research. In the cases of Sambong and Lagundi, the clinical studies of the academe helped the private sector navigate regulatory processes to facilitate market entry of the drug. In the case of the Axis Knee System, funding support from the public sector decreased the company's $R \& D$ risk, enabling them to deliver a low-cost product.

Another key factor is the availability of driven researchers undertaking tedious work required to deliver high quality research. The case studies highlighted the importance of good research and investment into research that can develop a good product.

It was evident that the early and sustained buy-in of the private sector was instrumental in the success of these products. An effective mechanism for initiating and sustaining public-private research engagement is vital in promoting collaboration between the two sectors. The ease of transactions between the two sectors facilitated by a focal communication person from the public sector helps greatly in the collaboration process.

The availability of funds is also a key success factor. The fact that public funds are available for private sector use in $\mathrm{R} \& \mathrm{D}$ activities, subject to approval, is the reason why the development of the Axis Knee System became a publicprivate partnership.

The government has a crucial role to play; among the main actions to take is to create a national innovation framework which will champion collaboration with the private sector. In 2013, the PNHRS Law paved the way for the Philippine National Health Research System, a framework to facilitate the collaboration and network of health research stakeholders, which include public and private entities. ${ }^{15}$ To stimulate greater private sector participation in health research, the framework should lay out guidelines for the academe and industry to follow when interacting with each other, based on best practices here or abroad. It should cover such aspects as funding, revenue sharing, technology licensing, and knowledge transfer. The aim is to reduce complexity by enabling information sharing among the different actors thereby consolidating efforts and reducing redundancies in requirements and processes. 


\section{CONCLUSION AND RECOMMENDATIONS}

The paper describes several roles of the private sector in health research and innovation. These include their role as the generator, funder, and adopter of health research and development. The experiences mentioned show that collaborations are possible and are mutually beneficial. Collaborations with the private sector in health research are vital in hastening to address health challenges in the Philippines. However, in order to stimulate more collaboration, commitment will be required from all players of the health research system.

Funding agencies should review the current financing and procurement mechanisms and make changes that will boost and maximize public-private partnerships. These include providing counterpart funding for researcher mobility into industry, for longer-term research programs, or small kick-start funds for exploratory collaborations. ${ }^{5}$ Administrative processes related to funding should also be reviewed. The PNHRS Law of 2013 could be amended to include research procurement provisions. For project collaboration, it is recommended that the renewal and evaluation process be performed a few months prior to the deadline to ensure that there will be no gap in the funding. Dowling recommends that the private sector co-fund research financing schemes with the government in the form of competitive research challenges. ${ }^{5,16}$ These competitions can be designed to enable strong relationships between participants who are academic experts and those who are industry players. These relationships could transform into long-term collaboration.

Aside from setting the tone in favor of collaboration, the government also has the important role of ensuring the effective brokerage of partnerships between the private sector and other members of the ecosystem. The Dowling Review suggests the use of digital tools which provide access to funding opportunities and services. ${ }^{5}$ More effort should be exerted in communicating to the private sector their opportunities to participate by acquiring or providing funds or services.

Finally, government could give incentive to private sector participation in health research. ${ }^{16}$ This could be as simple as providing tax incentives for funding early-stage research or as complex as working out a policy to favor locally-developed technology and products over foreign ones, specifically in government transactions.

Private businesses have the potential to invest in earlystage research, even when the technology is not yet ready for distribution and deployment. Doing this communicates that they are more willing to share the R\&D risk with the academe and the government. This will also direct efforts in applied research into being more use-based.

Finally, private sector can explore the potential of providing subsidy to training of the next generation of researchers who will discover and create new knowledge in their respective fields. Existing examples would be corporations, foundations, or banks that can co-subsidize grants, scholarships, or loan programs for Filipinos.

\section{Limitations of the paper}

This paper focuses on successful experiences based on three case studies. A better picture on the challenges, policies to be enhanced, and how to maximize current mechanisms will require data collection among groups/ agencies showing difficulty and barriers to participation. Furthermore, this is the first paper describing research participation by the private sector in the Philippines. We recognize that there is a lot of gaps in information, e.g. sources of private sector funding, types of research funded by private sector, capacity needs, and similar other information. We hope that this paper will inspire policy makers and researchers to investigate further how to maximize public-private collaboration in health research.

\section{Acknowledgments}

The proponents of this study would like to acknowledge the contributions of Ms. Reneepearl Kim Sales, Professor Marilyn Ellorin-Crisostomo, and Dr. Katherine VillegasReyes.

\section{Statement of Authorship}

All authors approved the final version submitted.

\section{Author Disclosure}

All authors declared no conflicts of interest.

\section{Funding Source}

This paper was funded by the Philippine Council for Health Research and Development.

\section{REFERENCES}

1. Olier C. The role of private sector in health care: challenging the myths [Internet]. Lecture presented at Oxfam; [cited 2018 Apr 4]. Available from: https://ec.europa.eu/health//sites/health/files/eu_world/docs/ ev_20121025_co04_en.pdf

2. Harding A. Center for Global Development [Internet]. Center for Global Development. 2009 Nov. [cited 2018 Apr 7]. Available from: https://www.cgdev.org/files/1423350_file_CGD_PSAF_Report_ web.pdf

3. Yoong J, Burger N, Spreng C, Sood N. Private sector participation and health system performance in Sub-Saharan Africa. PLoS One. 2010 Oct 7; 5(10):e13243.

4. Mugwagwa JT, Chinyadza JK, Banda G. Private sector participation in health care in Zimbabwe: what's the value-added? J Healthc Commun. 2017; 2:2. doi: 10.4172/2472-1654.100050.

5. The Dowling Review of Business-University Research [Internet]. 2015 [cited 2018Apr4]. Available from: www.raeng.org.uk/policy/ dowling-review/the-dowling-review-of-business-universityresearch\&p=DevEx.LB.1,5069.1.

6. Philippine Health Insurance Corporation (PhilHealth). Annual Report 2017 [Internet]. 2017 [cited 2018 Apr 4]. Available from: https://www.philhealth.gov.ph/about_us/annual_report/ar2017.pdf

7. Sussex J, Feng Y, Mestre-Ferrandiz J, et al. Quantifying the economic impact of government and charity funding of medical research on private research and development funding in the United Kingdom. BMC Med. 2016 Feb 24;14:32. 
8. Balabanova D, Oliveira-Cruz V, Hanson K. Health sector governance and implications for the private sector [Internet]. Washington DC: Result for Development Institute and The Rockefeller Foundation. 2008 [cited 2018 Apr 8]. Available from: https://www.r4d.org/wpcontent/uploads/Health-Sector-Governance-and-Implications-forthe-Private-Sector.pdf

9. Philippine Council for Health Research and Development [Internet]. [cited 2018 Apr 4]. Available from: http://www.pchrd.dost.gov.ph/ index.php/downloads/category/1-annual-report.

10. Fulo HM. Technology transfer in the Philippines [Internet]. Lecture presented at: Interregional expert meeting. [cited 2018 Apr 4]. Available from: https://www.wipo.int/edocs/mdocs/mdocs/en/wipo_ ssc_lim_15/wipo_ssc_lim_15_1.pdf

11. The Philippine Health Research Registry [Internet]. Philippine Council for Health Research and Development; [cited 2018 Apr 4]. Available from: http://registry.healthresearch.ph/

12. Pulumbarit ER. Commercialization of Medicinal Plant Products: A Success Story? [Internet]. [cited 2018 Apr 6]. Available from: https:// ipophil.gov.ph/images/IPKnowledge/TechnologyCommercialization SuccessStorybyElizabethPulumbarit.pdf
13. From Herbal Folklore to Modern Medicine [Internet]. World Intellectual Property Organization. 2013 [cited 2018 Apr 4]. Available from: http://www.wipo.int/ipadvantage/en/details.jsp?id=3661.

14. Science, Technology, Research and Innovation for Development (STRIDE) Philippines Innovation Ecosystem Assessment. Science, Technology, Research and Innovation for Development (STRIDE) Philippines Innovation Ecosystem Assessment. RTI International; 2014.

15. Philippine Congress. Republic Act No.10532. An Act Institutionalizing the Philippine National Health Research System. 2013.

16. Paderanga CW. Private Sector Assessment Philippines [Internet]. 2011 [cited 2018 Apr 4]. Available from: https://www.adb.org/sites/default/ files/institutional-document/32479/files/psa-philippines-2011.pdf.J Dermatol. 2012;51(6):697-701.

\title{
Have you read the current trends in
} Medical and Health Research in the Philippines?

\section{Acta Medica Philippina The National Health Science Journal}

\author{
Access Online: www.actamedicaphilippina.org
}

